\title{
PSYCHOLOGICAL WELLNESS CONSTRUCTS: RELATIONSHIPS AND GROUP DIFFERENCES
}

\author{
LIEZL GROPP \\ DIRK GELDENHUYS \\ DEL NE VISSER \\ geldedj@unisa.ac.za \\ Department of Industrial and Organisational Psychology \\ University of South Africa
}

\begin{abstract}
The objective of the study was to examine the relationships between several constructs that were hypothesised to be components underlying psychological wellness and to establish whether there were differences between managerial and non-managerial groups or between Black and White groups in respect of the wellness variables. The Personal Orientation Inventory (POI), Locus of Control Inventory (LOC), Sense of Coherence Scale (SOC), and the Bar-On EQ-I were administered to a random sample of 200 employees of a financial services company. Statistically significant differences were found between the groups on several of the wellness variables with the manager and White groups obtaining higher scores on these variables than their comparison groups. However, in respect of External Locus of Control, the non-manager and Black groups obtained the higher scores. Factor analytic results demonstrated that the wellness variables clustered in two correlated factors $(r=0,43)$ labeled psychological wellness and self-actualisation.
\end{abstract}

Key words: Psychological wellness, self-actualisation, locus of control, sense of coherence, emotional intelligence

The movement in the direction of positive psychology is accompanied by a shift towards the study of psychological wellness. Walsh and Shapiro (1983) stated that one of the primary reasons for the existence of psychology is to contribute to our understanding of psychological wellness and to enhance our ability to realise it. Positive psychology thus "offers a rare opportunity for a reorientation and reconstruction of our views of clinical psychology through a reconstruction of our views of psychological health and human adaptation and adjustment" (Snyder \& Lopez, 2002, p. 22).

Individuals' degree of psychological wellness is the result of their position on two independent dimensions, namely positive and negative affect (Bradburn, 1969). This view was supported by Cowen (1994), who indicated that wellness anchors one end of a hypothetical continuum and sickness (pathology) the other end. Furthermore, wellness is commonly conceptualised as having many dimensions (Adams, Bezner, Drabbs, Zambarano \& Steinhardt, 2000).

Despite the current interest in psychological wellness, little effort has been made in evaluating how psychological dimensions are related to overall wellness. Hence, there is no general agreement about how psychological wellness should be measured (Jahoda, 1958). Van Eeden (1996) also pointed out that there is little consensus between the different models and theories of psychological wellness. She stated that further research needs to be undertaken to understand the relationships between the theoretical conceptualisations and the empirical denotations of constructs related to psychological wellness. Compton's (2001, p. 486) conclusion about the present state of affairs was that "any investigator who is curious about the parameters of psychological wellness will find a confusing array of theoretical perspectives, conclusions and methodologies that all claim some authority in the literature".

Given the diversity of the South African population, the question arises whether there are differences in psychological wellness between the various population groups. Snyders and Lopez (2002) indicated that little had been done worldwide to determine the factors that might influence the meaning of health and the good life for individuals. They pointed out that societal and cultural contexts of life shape the perceptions of individuals to pursue identity development, goals and happiness. Cowen (1994) concluded that overt and covert expressions of values are built into any definition of wellness.
The implication of the findings of these authors is that one may expect differences between population groups regarding perceptions and levels of psychological wellness, because values differ across cultures as well as across subgroups. It appears that a uniformly acceptable definition of psychological wellness is an illusion (Cowen 1994).

In view of the apparent wide spectrum of research options suggested by the above, the main objective of the current study was to examine the relationships between several constructs that were hypothesised to be components underlying psychological wellness. A secondary purpose was to establish whether there were differences between managerial and non-managerial groups or between White and Black groups in respect of the wellness variables.

\section{Psychological wellness}

Psychological wellness falls within a broad field of study that examines quality of life issues that share many common characteristics, such as happiness, life satisfaction and morale (Kozma, Stones \& McNeil, 1991). It stands to reason that definitions of psychological wellness abounds.

Psychological wellness was defined by Cowen (1994) as a potentially fruitful orienting concept that directs attention to a family of genotypically unified phenomena of interest. It includes behavioural markers (having effective interpersonal relationships, mastering age- and ability-appropriate tasks) and psychological markers (having a sense of belonging and purpose, control over one's fate and satisfaction with one's existence and oneself).

Adams, Bezner and Steinhardt (1997) defined psychological wellness as the general perception experienced by individuals that there will be positive outcomes to events or circumstances. This definition refers to a psychic resource identified as dispositional optimism. Yet another definition was proposed by Compton (2001, p. 497) according to whom psychological wellness can be conceptualised by "a tripartite model that contains factors for subjective wellness, personal growth and a style of religiosity that is characterised by other centeredness". Snyder and Lopez (2002), however, stated that positive functioning comprises six dimensions of psychological wellness (self-acceptance, positive relationships with others, personal growth, purpose in life, environmental mastery and autonomy). 
Another dimensional model was proposed by Benjamin and Looby (1998) who viewed wellness as constituting six major dimensions, namely the physical, emotional, mental, social, occupational and spiritual dimensions. Optimum wellness is attained only when there is spiritual and personal balance in each of the six interconnected dimensions.

It is important to note that wellness is perceived as a relatively lasting state of mind that is characterised by continuous adaptation, general wellness and the realisation of personal potential in all dimensions of subsystems in the human system (Van Eeden, 1996). Thus psychological wellness is "not seen as an absolute but rather as an anchor point at the positive end of an adjustment continuum, as an ideal that we should strive concertedly to approach" (Cowen, 1994, p. 171).

In order to explore the multi-dimensional aspect of psychological wellness and the interaction between different dimensions, several models have been developed by researchers such as Johada (1958), Seeman (1989), Witmer and Sweeney (1992), Adams et al. (1997) and, more recently, Compton (2001). The following dimensions appear to be consistent in all the models (Gropp, 2006):

- aspects of the self (intrapersonal, affective or cognitive behaviour, spirituality, personal growth);

- other domains of life (interpersonal, social and contextual, in love and work) in which the self manifests itself.

These dimensions were supported in the work of Van Eeden (1996), who mentioned that the dimensions of psychological wellness can be divided into the different facets of individuals' lives, namely facets of the self, facets of cognition, facets of emotions, facets of behaviour, facets of social interaction, and facets of value alignments.

Taking the different definitions and models into consideration, it appears that psychological wellness is multi-dimensional, with optimal functioning occurring when these dimensions are in balance. Psychological wellness functions thus in a complex system that changes with time and place, as well as with the integration of the different dimensions.

In the present study a number of variables were identified which by their definitions might constitute dimensions of psychological wellness. These were self-actualisation, locus of control, sense of coherence and emotional intelligence.

\section{Self-actualisation}

The term self-actualisation originated from Goldstein in 1940 (Johada, 1958) and the theories of Maslow and Rogers also played an important role in the development of the concept (Stonefield, 1999). The theories indicated that individuals strive for perfection and attempt to realise their latent potential.

According to Maslow (1954), humans are born with instinctive needs that motivate them to grow and develop and to actualise themselves to become all that they are capable of becoming. A similar definition was proposed by Rogers (1961), namely that self-actualisation is growth and enhanced experience towards the goal of increased complexity of functioning in becoming everything individuals are capable of being.

Schulz (1994, p. 59) defined self-actualisation as "a never-ending growth process of purposeful striving, optimal development, and becoming a more fully functioning and mature individual. It is described as an end-of-being state of fullest realisation of one's potentials." Keegan (2002, p. 9) agreed with this definition, stating that self-actualisation is the essence of personal growth "embodied in episodic peak experiences, which occur when we get an insight into what it means to be human".

Further definitions include those of Snyder and Lopez (2002) and Benjamin and Looby (1998). Snyder and Lopez (2002) also focused on the growth process, whereas Benjamin and Looby
(1998) stated that self-actualised individuals have the ability to cope with change because of their flexibility and resilience. They have a sense of responsibility, acceptance, duty, obligation and commitment which allows such individuals to use their potential talent to the utmost.

Schulz's definition was used for the purpose of this study. The definition clearly links the construct of self-actualisation with psychological wellness. Johada (1958) referred to the essence of mental health as an ongoing process called selfactualisation, self-realisation, growth or becoming. Van Eeden (1996) also supported the relation between self-actualisation and psychological wellness.

According to Meyer, Moore and Viljoen (2003) the injunction to actualise the self does not play the same role in the daily life of traditional Africans as it does among Westerners. This might be ascribed to the collective domination of the community in African culture and the influence of different perceptions of time, even for urbanised Africans (Mbiti, 1990). Another argument is that due to milieu deficiencies and psychological handicaps, low socio-economic status groups in South Africa are caught in a spiral of poverty and deprivation, thereby experiencing serious obstruction to optimal self-actualisation (Pretorius \& Le Roux, 1998).

Regarding the relationship between self-actualisation and managing, Jung and Sosik's (2006) study identified selfactualisation as a personal attribute of managers who were rated high on charismatic leadership. According to Conger and Kanungo (1998), self-actualisation allows charismatic leaders to exert fundamental influence over their followers and produce extraordinary performance.

\section{Locus of control}

Locus of control is based on the social learning theory of Rotter and the attribution theory of Heider (Schepers, 1995). Rotter (1966, p.1) defined internal and external locus of control as:

"When a reinforcement that is perceived by the subject as following some action of his own but not being entirely contingent upon his action, then, in our culture, it is typically perceived as the result of luck, chance, fate as under the control of powerful other, or as unpredictable because of great complexity of the forces surrounding him. When the event is interpreted in this way by the individual, we have labelled this a belief of external control If the person perceives that the event is contingent upon his own behaviour or his own relatively permanent characteristics, we have termed this a belief in internal control."

The above definition has also been used in a number of South African studies (Bothma \& Schepers, 1997; Els, Linde \& Rothmann, 2001; Le Roux, Schmidt \& Schepers, 1997). According to Schepers (1995) and Sunbul (2003), Rotter's social learning theory distinguishes between individuals who have an internal locus of control (belief that reinforcement of their behaviour is dependent on own achievements, abilities and commitment) and those who have an external locus of control, that is believing that luck, fate and influential people are responsible for reinforcement of their behaviour.

The social learning theory of Rotter (1966) explains the nature of reinforcement from the social environment and the influence that this reinforcement has on the future behaviour of individuals. In conjunction with the social learning theory, the attribution theory of Heider (1958) provides a basis on which individuals gain information on the stable or fluctuating qualities of other people (such as motives, intentions and characteristics). Individuals thus try to determine the origin of their own as well as others' behaviour.

Lefcourt (1981) expanded Rotter's definition by adding that the internal-external control construct was conceived as a generalised expectancy to perceive reinforcement either as contingent upon 
one's own behaviour (internal control) or as the result of forces beyond one's control and due to chance, fate or powerful others (external control).

Locus of control is a common criterion used for distinguishing psychological wellness (Bradburn, 1969). Research by Phillips (1980), Reker (1977), Yarnell (1971) and Sammon, Reznikoff and Geisenger (1985) indicated a positive correlation between internal locus of control and psychological wellness. Individuals who are psychologically well have an enduring sense of personal control (Adams et al., 2000). Witmer and Sweeny (1992) pointed out that individuals with a sense of inner control are more likely to collect information about disease and health maintenance to enable them to improve health habits and implement preventive care.

The link between internal locus of control and management performance is well established (Adeyemi-Bello, 2001; Klein \& Wasserstein-Warnet, 2000). Individuals with an internal locus of control are likely to have faith in their ability to achieve self-appointed objectives and to transform their environment, they take personal responsibility for their job success, and they display a deep involvement in planning and implementing work projects (Klein \& Wasserstein-Warnet, 2000).

Regarding cultural differences, most research findings support the notion that black people have a more external locus of control than white people (Ayalon \& Young, 2005). This is commonly contributed to the fact that black people are more likely to attribute mental illness to external agents outside the person, such as the role of ancestors, malignant spirits and sorcerers (Ayalon \& Young, 2005; Meyer et al., 2003). Another interpretation is that black people, as members of a disadvantaged ethnic group, had more limited access to opportunities (Ayalon \& Young, 2005; Galanos, Strauss \& Pieper, 1994; Wade, 1996).

\section{Sense of coherence}

Sense of coherence (SOC) is based on the work of Antonovsky (1993, p. 725) who defined the concept as:

“... a global orientation that expresses the extent to which one has a pervasive enduring though dynamic feeling of confidence that (1) the stimuli deriving from one's internal and external environment in the course of living are structured, predictable and explicable; (2) the resources are available to one to meet the demands posed by these stimuli; and (3) these demands are challenges worthy of investment and engagement."

According to Heiman (2004) and Visser (1994), Antonovsky's theoretical model addresses the relationship between psychological optimisation and SOC. Str mpfer (1990) and Visser (1994) noted that Antonovsky introduced the concept of generalised resistance resources that assist with the facilitation of effective tension management in any situation of demand. These generalised resistance resources, namely physical and biochemical, artefactual-material, cognitive, emotional, coping, interpersonal-relational and macro-sociocultural (Str mpfer, 1990; Visser, 1994), allow individuals to make sense of all the stressors confronted on a day-to-day basis (Visser, 1994).

Antonovsky and Sourani (1988) described SOC as referrring to the extent to which one sees one's world as comprehensible, manageable and meaningful. These integrated components can be described as follows (Heiman, 2004; Str mpfer, 1990; Van Eeden, 1996):

- Comprehensibility - the extent to which individuals see stimuli as clear, ordered, structured and consistent information at present, as well as in the future. These perceptions thus make cognitive sense.

- Manageability - the extent of individuals' perceptions that the necessary resources are adequate and available.
- Meaningfulness - the extent to which individuals feel that life makes sense emotionally rather than cognitively.

Str mpfer (1990) indicated that SOC is a dispositional orientation and not a state or a trait. It embraces components of perception, memory, information processing and effect into habitual patterns of appraisal and develops through repeated experiences of making sense of countless stressors in an individual's life. Through the repeated exposure of these experiences of sensemaking, an individual develops a strong sense of coherence over time.

SOC refers thus to individuals' orientation to life crises and the ability to react to stressors in a positive manner (Van Eeden, 1996). Individuals with a high SOC tend to be better adjusted and are able to make the necessary adjustments in life to be stable and productive individuals. (Strauser \& Lustig, 2003).

There are clear links between SOC and psychological wellness in the literature. Antonovsky noted that although our language had a word to describe the processes by which disease unfolds, no parallel word was identified to describe the processes that favour healthy outcomes (Cowen, 1994). Walker (2002) confirmed this by stating that a sense of coherence is an important determinant of psychological wellness.

Van Eeden (1996) described SOC as a dispositional orientation and a dynamic aspect of psychological wellness. Moomal (1999) confirmed this view by pointing out that several studies have explored the relationship between psychological well-being and meaning or purpose in life as operationalised by different instruments, such as the Life Attitude Profile, the Purpose in Life Test and the Sense of Coherence Scale.

SOC relates to the probability of exploiting potential resources to meet the demands imposed upon individuals (Antonovsky, 1987). Individuals with a high SOC thus have a greater ability to mobilise and generate resources in their workplace than employees with a low SOC. For instance, it was found that SOC predicted influence and assistance from others at work (Kalimo \& Vuori, 1991). Feldt, Kivimaki, Rantala and Tolvanen (2004) also found that managers' mean level of SOC was relative high in comparison with the average SOC of employees in other studies.

Although no reports on the influence of cultural differences on SOC could be found in the literature, the African ontological view might, as in the case of other hypothesised wellnessconstructs, account for different levels of SOC between black and white people. According to this view of the meso-cosmos, "... the day-to-day psychological fate of individual human beings is modulated by a subtle dialectic of complex (often ambiguous) relations between humans and the creatures of the meso-cosmos ..." (Sow, 1980 as quoted by Meyer et al., 2003).

\section{Emotional intelligence}

The phrase emotional intelligence (EQ) was first used by Peter Salovey and John Mayer (Gibbs, 1995; Goleman, 1998; Schutte \& Malouff, 1998). Salovey and Mayer (1993) defined EQ as the ability to regulate one's own feelings and to use feelings to guide thoughts and actions. Goleman (1998) added that EQ refers to the capacity to recognise our own feelings and those of others in motivating ourselves, and for managing emotions in ourselves and in our relationships. Reuven Bar-On (1997) defined EQ as an array of non-cognitive capabilities, competencies and skills that influence one's ability to succeed in coping with environmental demands and pressures. The latter definition will be adopted for the purpose of this study.

Walker (2002, p. 3) stated that "mental health can be seen as knowing or cognition while emotional health relates more to feeling". Goleman (1998) demonstrated the importance of EQ by stating that emotional intelligence is the guide to fine-tuning on-the-job performance of every kind, managing unruly feelings, 
keeping motivated, tuning in with accuracy to the feelings of others, and developing good work-related social skills, including those essential for leadership and teamwork. Success demands more than intellectual excellence or technical prowess. People therefore need another sort of skill to survive and thrive in the increasingly turbulent job market. Internal qualities such as resilience, initiative, optimism and adaptability are taking on a new valuation (Goleman, 1998).

Emotional intelligence is described as a hidden advantage for success (Cooper \& Sawaf, 1998; Goleman, 1998). EQ is therefore not only an important factor in determining the ability to succeed in life; it also influences general psychological wellness (Bar-on, 1997). Empirical research indicated that managers who scored high on EQ suffered less subjective stress, experienced better health and well-being, and demonstrated better management performance than managers who scored low on EQ (Slaski \& Cartwright, 2002).

EQ is viewed as a key determinant of effective management and leadership (Fernandez, 2007), supported by empirical evidence (Kerr, Garvin, Heaton \& Boyle, 2006). For instance, Palmer, Walls, Burgess and Stough (2001) found correlations between EQ and several components of effective leadership, in particular that EQ accounts for how effective leaders monitor and respond to subordinates and make them feel at work.

Regarding cultural differences, Salovey, Mayer and Caruso (2002) indicated that it still has to be investigated whether EQ is culture bound.

From the above, it appears likely that the chosen constructs, namely self-actualisation, locus of control, sense of coherence and emotional intelligence, share a common theme that humans are conscious entities who have the freedom to make choices from the alternatives available to them (Jordaan \& Jordaan, 1992). It also appears that these four constructs are somehow related to psychological wellness. This assumption has been confirmed by previous research (Bar-On, 1997; Jahoda, 1958; Moomal, 1999; Van Eeden, 1996; Walker, 2002) that has linked these constructs to psychological wellness.

The following hypotheses were therefore tested in the present study:

Hypothesis 1: Self-actualisation, locus of control, sense of coherence and emotional intelligence are components underlying psychological wellness.

Hypothesis 2: Managerial and non-managerial subgroups differ with regard to self-actualisation, locus of control, sense of coherence and emotional intelligence.

Hypothesis 3: Black and white subgroups differ with regard to self-actualisation, locus of control and sense of coherence and emotional intelligence.

\section{RESEARCH DESIGN}

\section{Research approach}

A cross-sectional design employing questionnaire data was used. The data were analysed by means of quantitative statistical methods.

\section{Participants}

The participants were employees from the head office of a financial services company in South Africa. A random sample of 200 employees was selected from a population of 1399 individuals to participate in the project. The business language of the company was English and therefore the employees were all proficient in English. A minimum educational requirement for employment at the company was matriculation.
With regard to tenure, $55,8 \%$ of the participants had worked at the company for less than three years and $18,5 \%$ had worked there for three to six years. The remainder $(25,5 \%)$ had been employed for more than six years. Most of the employees $(79,5 \%)$ were 34 years of age or younger and the mean age was 30,38 years $(S D=6,17)$. There were 124 females and 76 males.

The participants could be differentiated with regard to their responsibilities and they were split into two groups on the basis of their managerial responsibilities. There were 35 employees with management responsibilities $(17,5 \%)$ as against 165 employees without management responsibilities $(82,5 \%)$. The distribution of the sample with regard to ethnic group yielded the following results: There were 31 Africans (15,5\%), 22 Coloureds (11\%), 17 Asians (8,5\%) and 130 Whites (65\%). For the comparisons between the Black and White subgroups, the Africans, Coloureds and Asians were grouped together.

\section{Measuring instruments}

Four measuring instruments representing constructs associated with psychological wellness were administered to the respondents, namely the Personal Orientation Inventory (POI), the Locus of Control Inventory (LOC), the Sense of Coherence Scale (SOC), and the Bar-On EQ-i.

\section{Personal Orientation Inventory (POI)}

The Personal Orientation Inventory was developed by Shostrom (1974) to provide a standardised instrument for the measurement of values and behaviour hypothesised to be important in the development of self-actualised individuals (Knapp, 1976). In the present study it was therefore included to measure the participants' levels of self-actualisation. It is a 150 -item selfreport inventory that is based on the humanistic-existential theories of Maslow, Rodgers, Perls and Riesman (Hjelle \& Ziegler, 1976; Visser, 1994). The items in the POI are paired opposites, because each concept is described as a positive and a negative statement (Knapp, 1976). Individuals are instructed to select single statements from the pairs of statements that are most relevant to themselves. A scoring template is placed over the answer sheet to determine the raw scores for the various scales. High scores indicate high levels of self-actualisation and vice versa (Stonefield, 1999).

The POI sub-scales (two main scales plus ten additional scales) are normative and give a combined profile for the respondents' self-actualisation, although the scales must be interpreted independently (Schulz, 1994; Stonefield, 1999). In addition, there are two ratio scales, the Time Orientation and Support Orientation Scales, which play an important role in personal development and interpersonal development (Knapp, 1976; Shostrom, 1974). In the present study only the main scales will be used, because Shostrom (1974) recommended that the Time Competence (Tc) and Inner-Directed (I) scales may be used when a quick estimate of examinees' levels of self-actualisation is desired. Furthermore, the Time Competence and Inner-Directed scales use all the items in the POI and are the only POI scales that do not have overlapping items.

- The Time Competence (Tc) scale consists of 23 items and is used to measure the degree to which an individual is present tense oriented. Self-actualising individuals are time competent and appear to live in the present rather than in the past or future (Shostrom, 1974). They are able to tie the past and the future to the present in meaningful continuity and their aspirations are tied meaningfully to present working goals. They are characterised by faith in the future without rigid or overidealised goals. Individuals who obtain low scores on the Tc scale tend to live primarily in the past or the future and are bound by past guilt, regrets, resentments, and hostilities, or by unrealistic expectations, goals, plans or fears of the future (Knapp, 1976)

- The Inner-Directed (I) scale consists of 127 items and is used to measure whether individuals' value reactions are primarily "self' or "other" oriented. For inner-directed individuals, 
internal motivations are their guiding forces as opposed to external influences (Shostrom, 1974). Other-directed individuals are guided primarily by their peers or other outside influences and tend to be dependent (Knapp, 1976).

The most important test for validity of the POI is that it should discriminate between individuals who have attained high levels of self-actualisation and those who have lower levels of selfactualisation, as was found by Shostrom $(1964 ; 1974)$.

With regard to reliability, a one-week-interval test-retest study by Klavetter and Moagar (1967) resulted in reliability coefficients for the main scales of Time competence (Tc) and Inner-Direction (I) of 0,71 and 0,77 respectively. The split-half reliability coefficient based on an odd-even split of the 150 items of the POI for a South African sample was found to be 0,73 (Van Wyk, 1978). He also obtained an internal consistency coefficient of 0,72 by using Kuder-Richardson's Formula 20 (KR-20).

\section{Locus of Control Inventory (LOC)}

The locus of control concept stems from Heider's attribution theory and Rotter's social learning theory (Bothma \& Schepers, 1997; Els, 1999). The revised 88-item LOC inventory was developed to measure locus of control based on the following three factors (Schepers, 1995; 1999):

Internal control: The belief that performance is dependent on capabilities, behaviour or personal qualities in one's own control (Els, 1999). Thirty-four items are related to this factor.

External control: Individuals' beliefs that their performance is related to things outside their control, such as fate, luck, circumstances or influential people (Els, 1999). There are 26 items related to this factor.

Autonomy: Els (1999) stated that this scale measures whether respondents trust their own ability, can function confidently with independence and can come to their own decisions for problem solving. Twenty-eight items in the inventory determine this factor.

Individuals with high scores on internal control and autonomy and low scores on external control are regarded as well-adapted and healthy individuals who are able to cope effectively with life's stresses. Individuals with high scores on external control tend to blame the environment for non-performance or life crises.

The construct validity of the LOC was investigated by correlating its scales with scales of the 16PF Questionnaire, the Jung Personality Questionnaire, the 19-Field Interest Questionnaire, the Personal, Home, Social and Formal Relation Questionnaire, the Survey of Study Habits and Attitudes, and the Career Development Questionnaire (Schepers, 1995). In a later study, it was found that Internal Control and Autonomy correlated positively with sense of coherence and emotional intelligence, whereas External Control correlated negatively with these variables (Schepers, Gropp \& Geldenhuys, 2006).

Internal consistency alphas of the original questionnaire scales were 0,80, 0,77 and 0,80 for External Control, Internal Control and Autonomy, respectively (Schepers, 1995). The Cronbach alpha coefficients of the 1999 version were 0,88 (Autonomy), 0,87 (External Control) and 0,82 (Internal Control) (Els, 1999; Schepers, 2004; Schepers, Gropp \& Geldenhuys, 2006).

\section{Sense of Coherence (SOC) Scale}

The Sense of Coherence (SOC) Scale was developed to measure the sense of coherence construct which is a global orientation to one's inner and outer environments (Antonovsky, 1993). In South Africa the SOC Scale has been used widely to assess relationships between sense of coherence and other psychological wellness constructs (Breed, Cilliers \& Visser, 2006; Cilliers \& Coetzee, 2003; Du Toit, Coetzee \& Visser, 2005; Str mpfer \& Wissing, 1998; Van Eeden, 1996; Walker, 2002).
The SOC Scale consists of 29 five-facet items with a sevenpoint semantic differential scale with two anchoring phrases (Antonovsky, 1993). Every item includes four facets that describe the stimulus plus a fifth SOC facet that expresses one of the three components of sense of coherence (comprehensibility, manageability or meaningfulness). There are 11 items for the comprehensibility dimension, ten items for manageability, and eight items for meaningfulness. Thirteen negatively phrased items are included, but the scale is scored so that a high score indicates a strong sense of coherence. Although the scale yields scores on each of the three dimensions, the SOC was developed to measure primarily the sense of coherence as a global orientation (Antonovsky, 1993).

The reliability and validity of the SOC Scale has been demonstrated across cultures, social classes, ethnic groups, gender groups and age groups (Antonovsky, 1993). In his summary of the findings of 29 researchers, Antonovsky (1993) reported alpha coefficients ranging between 0,82 and 0,95 . Test-retest reliabilities varied between 0,52 and 0,97. In their review of 30-odd South African studies on the SOC, Str mpfer and Wissing (1998) reported that the mean alpha coefficient across all studies was 0,87 . Subsequently, Breed, Cilliers and Visser (2006) obtained alphas of 0,88 and 0,83 on the SOC composite for white and African groups, respectively. In another South African study, Du Toit, Coetzee and Visser (2005) obtained a Cronbach alpha of 0,88 for the SOC composite.

A wealth of construct validity evidence has been obtained by South African researchers that published correlations between scores on the SOC Scale and various other measures (Str mpfer \& Wissing, 1998). An exploratory factor analysis conducted on the SOC Scale yielded interpretable single and two-factor structures (Breed, Cilliers \& Visser, 2006). The factors of the two-factor solution were labelled as Meaningfulness and Comprehensibility. Breed, Cilliers and Visser (2006) furthermore investigated the factor structure of six salutogenic constructs, namely sense of coherence, hardiness, learned resourcefulness, potency, internal locus of control and selfefficacy, and obtained a single factor structure. Since empirical verification of the three-factor structure of sense of coherence as initially conceptualised could not be found, Antonovsky (1987) later conceded that sense of coherence should be regarded as a single-dimensional construct. This viewpoint was also supported by Frenz, Carey and Jorgensen (1993) who obtained intercorrelations of 0,71 or higher between the three subscales. In view of these results, the use of composite scores on the SOC Scale is therefore indicated.

\section{Bar-On EQ-i}

The Bar-On EQ-i was used for measuring emotional intelligence by providing information on respondents' ability to deal with environmental demands and pressures (Bar-On, 1997). The inventory had been used in South Africa and several of its validity studies are based on South African samples (BarOn, 1997). Walker (2002) also identified correlations between psychological wellness constructs and the Bar-On EQ-i within a South African context.

The 133-item self-report inventory measures 15 dimensions of emotional intelligence (the conceptual components) that are further combined to yield scores on five sub-scales, namely the Intrapersonal, Interpersonal, Adaptability, Stress Management, and General Mood Scales. Composite scores, consisting of the sum of all the sub-scales, are also calculated to provide overall emotional intelligence scores. High scores on the scales indicate that emotional skills are well developed and functional in the respondent (BarOn, 1997). The Bar-On EQ-I also includes three validity subscales (Schutte \& Malouff, 1993).

Convergent and discriminant validity evidence was obtained by correlating the EQ-i sub-scale scores with scores on the scales of various other measures (Bar-On, 1997). The internal 
consistencies of the sub-scales were examined by computing Cronbach's alpha and the results proved to be satisfactory (BarOn, 1997). To establish the test-retest reliabilities of the Bar-On EQ-I two South African groups were used with a retest period of one and four months respectively. The mean reliability coefficient after one month was 0,85 and after four months it was 0,74 (Bar-On, 1997).

\section{Procedure}

The randomly selected sample was requested to attend a two-and-a-half-hour session in groups of 20 to 30 people. During the session they completed a biographical inventory designed for the purpose of this study and the four paper-based inventories. After 12 sessions, the full sample had completed the inventories.

\section{RESULTS}

The first step in the analysis of the data entailed computing descriptive statistics for the study variables. Thereafter tests were conducted to establish whether the hypothesised differences between managerial and non-managerial groups and also between the population groups were found in respect of the psychological wellness variables. Finally, the relationships between the wellness variables were examined and an exploratory factor analysis (EFA) was performed to determine whether the variables clustered together to form a general psychological wellness factor.

Descriptive statistics for the variables are reported in Table 1.
TABLE 1

DESCRIPTIVE STATISTICS OF THE PSYCHOLOGICAL WELLNESS VARIABLES $(\mathbf{N}=\mathbf{2 0 0})$

\begin{tabular}{|c|c|c|c|c|c|c|c|}
\hline Variable & $\begin{array}{l}\text { Num- } \\
\text { ber of } \\
\text { items }\end{array}$ & Min & Max & $\mathbf{M}$ & SD & $\begin{array}{c}\text { Skew- } \\
\text { ness }\end{array}$ & $\begin{array}{l}\text { Kur- } \\
\text { tosis }\end{array}$ \\
\hline \multicolumn{8}{|c|}{ Personal Orientation Inventory (POI) } \\
\hline Time Competence, Tc & 23 & 7 & 24 & 15,32 & 2,91 & 0,04 & 0,10 \\
\hline Inner-directed, I & 127 & 39 & 103 & 78,43 & 11,02 & $-0,53$ & 0,48 \\
\hline \multicolumn{8}{|c|}{ Locus of Control Inventory (LOC) } \\
\hline Internal & 34 & 125 & 196 & 167,17 & 13,33 & $-0,28$ & $-0,11$ \\
\hline External & 26 & 35 & 128 & 84,88 & 19,91 & $-0,10$ & $-0,26$ \\
\hline Autonomy & 28 & 131 & 233 & 187,04 & 20,37 & $-0,37$ & $-0,22$ \\
\hline \multicolumn{8}{|c|}{ Sense of Coherence (SOC) } \\
\hline Comprehensibility & 11 & 28 & 77 & 47,91 & 9,15 & 0,22 & 0,02 \\
\hline Manageability & 10 & 29 & 70 & 49,99 & 8,12 & $-0,13$ & $-0,21$ \\
\hline Meaningfulness & 8 & 27 & 56 & 44,57 & 6,33 & $-0,35$ & $-0,44$ \\
\hline SOC Total & 29 & 89 & 190 & 142,48 & 20,13 & 0,04 & $-0,21$ \\
\hline \multicolumn{8}{|l|}{ Bar-On EQ-i } \\
\hline Intrapersonal & 40 & 60 & 134 & 100,69 & 14,55 & $-0,25$ & $-0,19$ \\
\hline Interpersonal & 29 & 60 & 129 & 97,83 & 14,50 & $-0,24$ & $-0,30$ \\
\hline Adaptability & 26 & 68 & 135 & 100,44 & 13,38 & 0,14 & $-0,37$ \\
\hline Stress Management & 18 & 54 & 135 & 98,78 & 15,05 & $-0,16$ & 0,06 \\
\hline General Mood & 17 & 62 & 127 & 100,77 & 13,07 & $-0,26$ & $-0,32$ \\
\hline Bar-On EQ-I Total & 130 & 62 & 137 & 99,42 & 13,75 & 0,04 & $-0,23$ \\
\hline
\end{tabular}

TABLE 2

COMPARISONS BETWEEN MEANS OF THE MANAGERIAL AND NON-MANAGERIAL GROUPS $(\mathbf{N}=\mathbf{2 0 0})$

\begin{tabular}{|c|c|c|c|c|c|c|c|c|c|}
\hline \multirow[b]{2}{*}{ Variable } & \multicolumn{2}{|c|}{$\begin{array}{l}\text { Managerial group } \\
\qquad \mathrm{N}=35\end{array}$} & \multicolumn{2}{|c|}{$\begin{array}{l}\text { Non-managerial group } \\
\qquad \mathrm{N}=165\end{array}$} & \multicolumn{2}{|c|}{$\begin{array}{l}\text { Homogeneity of } \\
\text { variances }\end{array}$} & \multicolumn{3}{|c|}{ Equality of means } \\
\hline & $\mathbf{M}$ & SD & $\mathbf{M}$ & SD & Levene $\mathrm{F}$ & $\mathbf{p}$ & $\mathbf{F}$ & $\mathrm{p}$ & $\begin{array}{l}\text { Estimated effect } \\
\text { size partial eta }\end{array}$ \\
\hline \multicolumn{10}{|c|}{ Personal Orientation Inventory (POI) } \\
\hline Time Competence, Tc & 16,17 & 2,66 & 15,14 & 2,94 & 0,56 & 0,456 & 3,67 & 0,057 & \\
\hline Inner-directed, I & 80,77 & 9,50 & 77,93 & 11,28 & 0,44 & 0,509 & 1,93 & 0,167 & \\
\hline \multicolumn{10}{|c|}{ Locus of Control Inventory (LOC) } \\
\hline Internal & 164,91 & 9,92 & 167,64 & 13,92 & 3,67 & 0,057 & 1,21 & 0,272 & \\
\hline External & 72,31 & 18,39 & 87,54 & 19,24 & 0,05 & 0,823 & 18,36 ** & 0,000 & 0,29 \\
\hline Autonomy & 193,77 & 13,92 & 185,61 & 21,25 & $7,37 *$ & 0,007 & $4,73 *$ & 0,031 & 0,15 \\
\hline \multicolumn{10}{|c|}{ Sense of Coherence (SOC) } \\
\hline Comprehensibility & 51,17 & 8,02 & 47,22 & 9,25 & 1,51 & 0,221 & $5,51 *$ & 0,020 & 0,16 \\
\hline Manageability & 52,37 & 7,01 & 49,48 & 8,26 & 2,05 & 0,154 & 3,72 & 0,055 & \\
\hline Meaningfulness & 47,46 & 5,31 & 43,96 & 9,38 & 2,97 & 0,086 & $9,18 * *$ & 0,003 & 0,21 \\
\hline SOC Total & 151,00 & 15,85 & 140,67 & 20,52 & 2,03 & 0,156 & $7,86^{* *}$ & 0,006 & 0,19 \\
\hline \multicolumn{10}{|l|}{ Bar-On EQ-i } \\
\hline Intrapersonal & 103,63 & 11,19 & 100,06 & 15,12 & $4,55^{*}$ & 0,034 & 1,74 & 0,188 & \\
\hline Interpersonal & 100,60 & 11,93 & 97,24 & 14,95 & $4,65^{*}$ & 0,032 & 1,55 & 0,214 & \\
\hline Adaptability & 104,20 & 11,47 & 99,64 & 13,64 & 1,83 & 0,178 & 3,40 & 0,067 & \\
\hline Stress Management & 103,91 & 15,35 & 97,68 & 14,80 & 0,23 & 0,633 & $5,05^{*}$ & 0,026 & 0,16 \\
\hline General Mood & 103,14 & 10,60 & 100,26 & 13,51 & 2,68 & 0,103 & 1,41 & 0,237 & \\
\hline Bar-On EQ-I Total & 103,29 & 11,49 & 98,60 & 14,08 & 2,23 & 0,137 & 3,39 & 0,067 & \\
\hline
\end{tabular}

* Significant at 0,05 level

** Significant at 0,01 level 
$\mathrm{F}$ tests were performed to determine whether there were statistically significant differences between the means of the managerial and non-managerial groups. In Table 2 the results of these tests are given in conjunction with the means and standard deviations of the groups. Partial eta was calculated as the estimated effect size. Significant differences between the groups were obtained for LOC External Control $(\mathrm{F}=18,36, \mathrm{p}<0,001)$, LOC Autonomy $(\mathrm{F}=4,73, \mathrm{p}=0,031)$, SOC Comprehensibility ( $\mathrm{F}$ $=5,51, p=0,020)$, SOC Meaningfulness $(F=9,18, p=0,003)$, SOC Total $(\mathrm{F}=7,86, \mathrm{p}=0,006)$, and EQ Stress Management $(\mathrm{F}=5,05$, $p=0,026)$. In every instance, except for LOC External Control, the managerial group obtained significantly higher mean scores on these variables. In the case of LOC External Control the nonmanagerial group obtained a higher mean than the managerial group. All of the estimated effect sizes represented small effects, except in the case of LOC External Control where a medium effect size was obtained.

In Table 3 the results of the $\mathrm{F}$ tests for equality of the means of the Black and White groups are reported. Statistically significant differences between the groups were obtained for LOC External Control $(F=5,30, p=0,022)$, SOC Comprehensibility $(F=9,01$, $p=0,003)$, SOC Meaningfulness $(F=6,19, p=0,014)$, SOC Total $(\mathrm{F}=7,66, \mathrm{p}=0,006)$, POI Time Competence $(\mathrm{F}=8,23, \mathrm{p}=0,005)$, and POI Inner-directed $(\mathrm{F}=5,88, \mathrm{p}=0,016)$. All of the partial etas represented small effect sizes. With the exception of LOC External Control, the White group scored significantly higher than the Black group.

The final step in the analysis of the data entailed exploring the relationships between the wellness variables. The matrix of intercorrelations is reported in Table 4 . The most striking feature of the matrix is that all of the intercorrelations were statistically significant on the $p \leq 0,05$ level. All of the variables were positively correlated, with the exception of LOC External
Control that correlated negatively with all the variables. Another feature is that strong intercorrelations were obtained between the subscales within each of the four measuring instruments, with the exception of LOC External Control. A small correlation was obtained between LOC External and Internal Control $(\mathrm{r}=$ $-0,18)$ and a moderate correlation was obtained between LOC External Control and Autonomy $(r=-0,36)$.

In view of the pattern of intercorrelations, we decided to conduct an EFA on the intercorrelations between the subscales of the measuring instruments to determine whether a general psychological wellness factor underlies scores on all of the variables. Since Antonovsky (1987) conceded that sense of coherence should be regarded as a single-dimensional construct (see also results obtained by Frenz, Carey and Jorgensen (1993) and by Breed, Cilliers and Visser (2006)) a single composite score on the SOC Scale was used in the EFA. In a study by Schepers, Gropp and Geldenhuys (2006), an EFA was performed on variables of the same data set, but their EFA was preceded by a principal components analysis (PCA) of the twelve POI subscales to reduce the number of variables of the POI to two factors which were then used in the EFA. Their PCA may have led to spurious results, because the main scales of the POI, Tc and I, contain all the items of the POI. All the other subscales are made up of combinations of the items, which means that Tc and I are the only subscales of the POI that do not have overlapping items (Shostrom, 1974). A follow-up EFA containing the variables as suggested, was therefore justified.

Before conducting the EFA, diagnostic tests were performed to ascertain whether the $11 \times 11$ intercorrelation matrix contained an adequate number of substantial pairwise correlations and also low partial correlations to justify conducting the factor analysis. The Kaiser Meyer - Olkin measure of sampling

TABLE 3

COMPARISONS BETWEEN MEANS OF THE BLACK AND WHITE GROUPS $(\mathbf{N}=\mathbf{2 0 0})$

\begin{tabular}{|c|c|c|c|c|c|c|c|c|c|}
\hline \multirow[b]{2}{*}{ Variable } & \multicolumn{2}{|c|}{$\begin{array}{c}\text { Black group } \\
\mathrm{N}=70\end{array}$} & \multicolumn{2}{|c|}{$\begin{array}{l}\text { White group } \\
\quad N=130\end{array}$} & \multicolumn{2}{|c|}{$\begin{array}{c}\text { Homogeneity of } \\
\text { variances }\end{array}$} & \multicolumn{3}{|c|}{ Equality of means } \\
\hline & $\mathbf{M}$ & SD & $\mathbf{M}$ & SD & Levene $\mathrm{F}$ & $\mathrm{p}$ & $\mathbf{F}$ & $\mathrm{p}$ & $\begin{array}{c}\text { Estimated effect } \\
\text { size d }\end{array}$ \\
\hline \multicolumn{10}{|c|}{ Personal Orientation Inventory (POI) } \\
\hline Time Competence, Tc & 14,53 & 3,10 & 15,75 & 2,73 & 0,25 & 0,618 & 8,23 & 0,005 ** & 0,20 \\
\hline Inner-directed, I & 75,89 & 11,82 & 79,80 & 10,35 & 1,35 & 0,248 & 5,88 & $0,016^{*}$ & 0,17 \\
\hline \multicolumn{10}{|c|}{ Locus of Control Inventory (LOC) } \\
\hline Internal & 168,13 & 14,60 & 166,65 & 12,62 & 0,33 & 0,567 & 0,56 & 0,454 & \\
\hline External & 89,24 & 19,27 & 82,52 & 19,92 & 0,23 & 0,632 & 5,30 & $0,022^{*}$ & 0,16 \\
\hline Autonomy & 185,00 & 21,16 & 188,13 & 19,93 & 0,00 & 0,999 & 1,08 & 0,301 & \\
\hline \multicolumn{10}{|c|}{ Sense of Coherence (SOC) } \\
\hline Comprehensibility & 45,31 & 9,69 & 49,31 & 8,57 & 1,74 & 0,189 & 9,01 & 0,003 ** & 0,21 \\
\hline Manageability & 48,81 & 9,05 & 50,62 & 7,53 & 1,53 & 0,218 & 2,26 & 0,135 & \\
\hline Meaningfulness & 43,07 & 6,80 & 45,38 & 5,94 & 1,56 & 0,213 & 6,19 & $0,014^{*}$ & 0,17 \\
\hline SOC Total & 137,20 & 22,26 & 145,32 & 18,35 & 2,09 & 0,150 & 7,66 & $0,006^{* *}$ & 0,19 \\
\hline \multicolumn{10}{|l|}{ Bar-On EQ-i } \\
\hline Intrapersonal & 100,06 & 16,31 & 101,02 & 13,57 & 3,12 & 0,079 & 0,20 & 0,655 & \\
\hline Interpersonal & 98,66 & 13,36 & 97,38 & 15,11 & 1,15 & 0,284 & 0,35 & 0,555 & \\
\hline Adaptability & 100,87 & 14,33 & 100,20 & 12,89 & 0,73 & 0,392 & 0,11 & 0,736 & \\
\hline Stress Management & 98,29 & 16,54 & 99,04 & 14,24 & 0,84 & 0,361 & 0,11 & 0,737 & \\
\hline General Mood & 99,09 & 12,65 & 101,67 & 13,25 & 0,23 & 0,634 & 1,78 & 0,183 & \\
\hline Bar-On EQ-I Total & 99,11 & 14,92 & 99,58 & 13,14 & 1,84 & 0,177 & 0,05 & 0,818 & \\
\hline
\end{tabular}


TABLE 4

INTERCORRELATIONS BETWEEN THE PSYCHOLOGICAL WELLNESS CONSTRUCTS

\begin{tabular}{|c|c|c|c|c|c|c|c|c|c|c|c|c|c|c|c|}
\hline \multirow[b]{2}{*}{ Variable } & \multirow[b]{2}{*}{ Time } & \multirow{2}{*}{$\begin{array}{c}\text { POI } \\
\text { Supp }\end{array}$} & \multirow[b]{2}{*}{ Int } & \multirow{2}{*}{$\begin{array}{r}\text { LOC } \\
\text { Ext }\end{array}$} & \multirow[b]{2}{*}{ Aut } & \multicolumn{3}{|c|}{ SOC } & \multirow[b]{2}{*}{ Total } & \multirow[b]{2}{*}{ Intra } & \multicolumn{3}{|c|}{ Bar-On EQ-i } & \multirow[b]{2}{*}{ Mood } & \multirow[b]{2}{*}{ Total } \\
\hline & & & & & & Comp & Manag & Mean & & & Inter & Adapt & Stress & & \\
\hline \multicolumn{16}{|l|}{ POI } \\
\hline Tc & 1,00 & & & & & & & & & & & & & & \\
\hline I & 0,54 ** & 1,00 & & & & & & & & & & & & & \\
\hline \multicolumn{16}{|l|}{ LOC } \\
\hline Internal & $0,16^{*}$ & $0,16^{*}$ & 1,00 & & & & & & & & & & & & \\
\hline External & $-0,23$ * * & $-0,26^{* *}$ & $-0,18^{*}$ & 1,00 & & & & & & & & & & & \\
\hline Autonomy & $0,20 * *$ & 0,40 ** & $0,62 * *$ & $-0,36$ ** & 1,00 & & & & & & & & & & \\
\hline \multicolumn{16}{|l|}{ SOC } \\
\hline Comprehensibility & $0,29 * *$ & $0,21 * *$ & $0,28 * *$ & $-0,37 * *$ & $0,44^{* *}$ & 1,00 & & & & & & & & & \\
\hline Manageability & $0,37 * *$ & $0,34^{* *}$ & 0,34 ** & $-0,48^{* *}$ & $0,52^{* *}$ & $0,61 * *$ & 1,00 & & & & & & & & \\
\hline Meaningfulness & 0,39 * * & $0,30^{* *}$ & $0,43^{* *}$ & $-0,32$ ** & 0,43 * * & $0,49 * *$ & $0,66^{* *}$ & 1,00 & & & & & & & \\
\hline SOC Total & 0,41 ** & $0,33^{* *}$ & 0,40 ** & $-0,46$ ** & $0,54 * *$ & $0,86^{* *}$ & $0,89 * *$ & 0,80 * * & 1,00 & & & & & & \\
\hline \multicolumn{16}{|l|}{ Bar-On EQ-i } \\
\hline Intrapersonal & 0,33 ** & $0,51 * *$ & 0,45 ** & $-0,38 * *$ & 0,69 ** & $0,53 * *$ & $0,64^{* *}$ & 0,57 * * & $0,68 * *$ & 1,00 & & & & & \\
\hline Interpersonal & 0,21 ** & $0,19 * *$ & $0,46 * *$ & $-0,18^{*}$ & $0,43 * *$ & 0,31 * * & $0,42^{* *}$ & $0,40 * *$ & $0,44^{* *}$ & $0,57 * *$ & 1,00 & & & & \\
\hline Adaptability & $0,20 * *$ & $0,23 * *$ & $0,44^{* *}$ & $-0,43 * *$ & $0,62^{* *}$ & 0,51 * * & $0,55^{* *}$ & $0,42^{* *}$ & $0,59 * *$ & $0,72 * *$ & 0,51 ** & 1,00 & & & \\
\hline Stress Management & $0,26^{* *}$ & $0,14^{*}$ & $0,30^{* *}$ & $-0,50^{* *}$ & $0,45^{* *}$ & $0,52^{* *}$ & 0,60 ** & 0,39 ** & 0,60 * * & $0,54^{* *}$ & 0,40 * * & $0,74^{* *}$ & 1,00 & & \\
\hline General Mood & 0,30 ** & $0,37 * *$ & $0,41 * *$ & $-0,23$ ** & $0,61 * *$ & 0,47 * * & 0,59 * * & $0,56^{* *}$ & $0,62 * *$ & $0,82^{* *}$ & $0,63 * *$ & 0,62 ** & $0,53 * *$ & 1,00 & \\
\hline Bar-On EQ-I Total & $0,32 * *$ & 0,37 * * & $0,50^{* *}$ & $-0,42^{* *}$ & 0,69 ** & $0,57^{* *}$ & $0,68^{* *}$ & $0,57^{* *}$ & 0,71 * * & $0,92 * *$ & $0,72 * *$ & 0,87 * * & $0,75^{* *}$ & $0,86^{* *}$ & 1,00 \\
\hline
\end{tabular}

* Significant at 0,05 level

** Significant at 0,01 level

TABLE 5

FACTOR ANALYSIS RESULTS FOR THE WELLNESS VARIABLES INCLUDING ONE-FACTOR, TWO-FACTOR AND THREE-FACTOR SOLUTIONS

\begin{tabular}{l|c|c|c|c|c|c|c|c|c}
\hline \multicolumn{7}{c}{ Single factor } \\
\hline & $\mathbf{1}$ & $\mathbf{h}^{\mathbf{2}}$ & $\mathbf{1}$ & $\mathbf{2}$ & $\mathbf{h}^{\mathbf{2}}$ & $\mathbf{1}$ & $\mathbf{2}$ & $\mathbf{3}^{\mathbf{*}}$ & $\mathbf{h}^{\mathbf{2}}$ \\
\hline POI Tc & $\mathbf{0 , 3 9}$ & 0,15 & 0,12 & $\mathbf{0 , 5 0}$ & 0,33 & $-0,00$ & $\mathbf{0 , 5 4}$ & 0,14 & 0,37 \\
\hline POI I & $\mathbf{0 , 4 4}$ & 0,19 & $-0,06$ & $\mathbf{0 , 9 8}$ & 0,92 & 0,10 & $\mathbf{0 , 9 1}$ & $-0,12$ & 0,82 \\
\hline LOC Internal & $\mathbf{0 , 5 5}$ & 0,30 & $\mathbf{0 , 5 8}$ & $-0,04$ & 0,32 & $\mathbf{0 , 6 7}$ & $-0,05$ & $-0,06$ & 0,39 \\
\hline LOC External & $-\mathbf{0 , 4 7}$ & 0,22 & $-\mathbf{0 , 4 2}$ & $-0,10$ & 0,22 & 0,07 & $-0,14$ & $-0,60$ & 0,38 \\
\hline LOC Autonomy & $\mathbf{0 , 7 6}$ & 0,58 & $\mathbf{0 , 7 1}$ & 0,10 & 0,57 & $\mathbf{0 , 6 9}$ & 0,10 & 0,07 & 0,60 \\
\hline SOC Total & $\mathbf{0 , 7 7}$ & 0,60 & $\mathbf{0 , 7 0}$ & 0,13 & 0,59 & $\mathbf{0 , 3 7}$ & 0,17 & $\mathbf{0 , 4 2}$ & 0,61 \\
\hline EQ-i Intrapersonal & $\mathbf{0 , 9 0}$ & 0,82 & $\mathbf{0 , 7 8}$ & 0,22 & 0,81 & $\mathbf{0 , 7 2}$ & 0,24 & 0,12 & 0,83 \\
\hline EQ-i Interpersonal & $\mathbf{0 , 6 2}$ & 0,38 & $\mathbf{0 , 6 5}$ & $-0,04$ & 0,40 & $\mathbf{0 , 7 1}$ & $-0,04$ & $-0,02$ & 0,47 \\
\hline EQ-i Adaptability & $\mathbf{0 , 8 0}$ & 0,65 & $\mathbf{0 , 9 1}$ & $-0,14$ & 0,73 & $\mathbf{0 , 5 1}$ & $-0,11$ & 0,50 & 0,74 \\
\hline EQ-i Stress Management & $\mathbf{0 , 6 9}$ & 0,47 & $\mathbf{0 , 7 7}$ & $-0,13$ & 0,53 & $\mathbf{0 , 1 4}$ & $-0,13$ & $\mathbf{0 , 8 5}$ & 0,79 \\
\hline EQ-i General Mood & $\mathbf{0 , 8 1}$ & 0,66 & $\mathbf{0 , 7 6}$ & 0,10 & 0,67 & $\mathbf{0 , 7 8}$ & 0,11 & $\mathbf{0 , 0 3}$ & 0,71 \\
\hline
\end{tabular}

* Factor was reversed

Factor loadings larger than 0,30 in bold

adequacy (MSA) was high at 0,84 . Bartlett's test of sphericity yielded a statistically significant approximate chi-square $\left[\mathrm{X}^{2}(55)=1296,35, \mathrm{p}<0,001\right]$. Furthermore, all the MSA's of the various items were larger than 0,60 . The results of these tests provided sufficient justification to proceed with the factor analysis.

Using the eigenvalue-larger-than-one criterion as indicating the number of factors to extract, a principal axis factor analysis was performed, extracting three factors that explained $71,30 \%$ of the variance. The factor matrix was subsequently rotated to a simple structure using the direct oblimin rotation procedure. The factor pattern matrix including the communalities associated with the scales are presented in Table 5. The POI subscales loaded highly on Factor 2 and SOC Total and EQ-I Adaptability were factorially complex, because these variables had substantial loadings on Factors 1 and 3. Furthermore, the correlation between Factors 1 and 3 was equal to 0,57 and the scree plot indicated the presence of two factors only. We therefore decided to extract two factors. This solution, which clustered all of the variables together in the first factor except for the two POI scales, explained $61,54 \%$ of the variance and is 
presented in Table 5. The correlation between the two factors was equal to 0,43 . In view of the single factor obtained by Schepers, Gropp and Geldenhuys (2006) for a second level factor analysis, we then decided to investigate the viability of a single factor solution. This solution, which is also reported in Table 5, explained $49,79 \%$ of the variance. Despite the fact that Factor 2 yielded only two substantial loadings (for POI Tc and POI I) for the two-factor solution, this solution appeared the most acceptable in view of its communality values, the percentage of variance explained, the correlations between the factors for the two-factor and three-factor solutions and the interpretability of the factors. The factors were labeled psychological wellness and self-actualisation.

\section{DISCUSSION}

The first objective of the study was to examine the relationships between dimensions of several constructs that were hypothesised to be components underlying psychological wellness, namely level of self-actualisation, locus of control, sense of coherence, and emotional intelligence. A second purpose was to establish whether there were differences between the means of managerial as opposed to non-managerial groups or between White and Black groups in respect of the wellness variables.

The hypothesis that the variables measured a single underlying construct of psychological wellness was not fully supported by the data, despite the fact that there were statistically significant correlations between all of the variables. Not fully in agreement with the solution proposed by Schepers, Gropp and Geldenhuys (2006), two factors appeared to provide the best description of the data. The dimensions of locus of control, sense of coherence, and emotional intelligence clustered together in a factor that was labeled psychological wellness. This means that there is a relation between individuals' inclination to attribute the control of events to themselves or to factors in the external environment, their positive orientation to life crises and ability to react to stressors in a positive manner, and their ability to regulate and cope with the emotions that environmental demands and pressures evoke.

For the second factor the POI variables, Time Competence and Inner-directed self-actualisation clustered together. The implication is that individuals who are present tense oriented, who are able to tie the past and the future to the present in meaningful continuity and whose aspirations are tied meaningfully to present working goals also tend to be inner-directed individuals whose internal motivations are their guiding force as opposed to external influences. The strong correlation between the two factors $(0,43)$ was nevertheless an indication of substantial shared variance between the factors. The two factors obtained in the present study confirm results obtained by Compton (2001) who proposed that a model for psychological wellness includes subjective wellness, which involves psychological adjustment and stress management aspects similar to Factor 1 above, and personal growth (self-actualisation similar to the POI scales that defined Factor 2). The third component that Compton (2001) included, other-centred religiosity, fell outside the scope of the present study.

When comparing the means of the managerial group with the non-managerial group with respect to the wellness variables, several hypothesised differences were obtained. The results with regard to locus of control indicated that managers were less inclined to ascribe their performance to matters outside of their control than non-managers. Furthermore, managers tended to trust in their own ability, functioned more independently and confidently, and managed to solve their own problems more readily than non-managers. With regard to sense of coherence, support was found for results obtained by Feldt et al. (2004). Managers obtained higher scores on Comprehensibility and Meaningfulness than non-managers. This implies that managers saw stimuli as clear, structured and consistent information and felt that life makes sense emotionally to a larger extent than non-managers do. Life therefore made more sense on the cognitive and emotional levels for managers than for non-managers. In respect of emotional intelligence, managers tended to endure stressful situations more effectively the non-managers. Managers were more able to remain calm, work under pressure and not leap to impulsive conclusions than non-managers. No group differences were obtained regarding self-actualisation.

Between the Black and White groups no differences were obtained regarding emotional intelligence, but on both scales of the POI significant differences were obtained. Whites displayed a higher degree of time competence and inner-directedness than Blacks. These results correspond with the views expressed by Mbiti (1990) and Pretorius and Le Roux (1998). Furthermore, Blacks were more inclined than Whites to believe that their performance was related to factors outside their control, such as fate, luck, circumstances or influential people. Differences between these groups were also obtained regarding sense of coherence, because Whites obtained higher scores on Comprehensibility and Meaningfulness than Blacks. The extent to which cultural differences regarding perception of these variables influenced the results, requires further investigation. For instance, the greater affinity of Blacks for LOC External Control, as was also found by Ayalon and Young (2005), might relate to cultural differences between Blacks and Whites regarding sense of community or group. Also, the reported differences should be interpreted with caution, because the sample was not representative of the South African population. The sample size furthermore did not permit comparisons between Blacks and Whites on similar levels of managerial responsibilities.

The contribution of the present study lies in the fact that more light was shed on correlates of the construct of psychological wellness and the study should be seen as an extension of the findings of Schepers, Gropp and Geldenhuys (2006). To a large extent the results also supported the hypotheses regarding group differences, thereby increasing our knowledge about individual differences regarding the various wellness constructs. In South Africa and abroad a wealth of research data has accumulated concerning psychological wellness. It is suggested that the time is ripe for the development of a broad wellness measuring instrument that includes all the aspects that hitherto have been associated with psychological wellness.

\section{ACKNOWLEDGEMENT}

We gratefully acknowledge the contribution of Ri t te Eiselen and staff members of the Statistical Consultation Service of the University of Johannesburg for assistance with the computer analyses.

\section{REFERENCES}

Adams, T.B., Bezner, J.R. \& Steinhardt, M.A. (1997). The conceptualisation and measurement of perceived wellness: Integrating balance across and within dimensions. Journal of American Health Promotion, 11 (3), 208-218.

Adams, T.B., Bezner, J.R., Drabbs, M.E., Zambarano, R.J. \& Steinhardt, M.A. (2000). Conceptualisation and measurement of the spiritual and psychological dimensions of wellness in a college population. Journal of American College Health, 48 (4), 165-173.

Adeyemi-Bello, T. (2001). Validating Rotter's (1996) Locus of Control scale with a sample of non-for-profit leaders. Management Research News, 24 (6/7), 25-34.

Ayalon, L. \& Young, M.A. (2005). Racial group differences in help-seeking behaviors. Journal of Social Psychology, 145 (14), 391-412. 
Antonovsky, A. (1987). Unravelling the mystery of health: How people manage stress and stay well. San Franscisco: JosseyBass.

Antonovsky, A. (1993). The structure and properties of the sense of coherence scale. Social Science and Medicine, 36 (6), 725733.

Antonovsky, A. \& Sourani, T. (1988). Family sense of coherence and family adaptation. Journal of Marriage and the Family, 50 (1), 79-92.

Bar-On, R. (1997). BarOn Emotional Quotient Inventory - Technical Manual. Toronto: MultiHealth System.

Benjamin, P., Looby, J. (1998). Defining the nature of spirituality in the context of Maslow's and Rogers's theories. Counseling and Values, 42 (2), 92-100.

Bothma, A.C. \& Schepers, J.M. (1997). The role of locus of control and achievement motivation in the work performance of black managers. Journal of Industrial Psychology, 23 (3), 4452.

Bradburn, N.M. (1969). The structure of psychological wellbeing. Chicago: Aldine.

Breed, M., Cilliers, F. \& Visser, D. (2006). The factor structure of six salutogenic constructs. South African Journal of Industrial Psychology, 32 (1), 74-86.

Cilliers, F. \& Coetzee, S.C. (2003). The theoretical-empirical fit between three psychological wellness constructs: Sense of coherence, learned resourcefulness and self-actualisation. South African Journal of Labour Relations, 27 (1), 4-24.

Compton, W.C. (2001). Towards a tripartite factor structure of mental health: Subjective wel-being, personal growth and religiosity. Journal of Psychology, 135 (5), 486 -500.

Conger, J.A. \& Kanungo, R.N. (1998). Charismatic leadership in organizations. Thousand Oaks, CA: Sage.

Cooper, R. \& Sawaf, A. (1997). Executive EQ. London: Orion.

Cowen, E.L. (1994). The enhancement of psychological wellness: Challenges and opportunities. American Journal of Community Psychology, 22 (2), 149-179.

Du Toit, F. Coetzee, S. \& Visser, D. (2005). The relation between personality type and sense of coherence among technical workers. Southern African Business Review, 9(1), 51-65.

Els, D.A., (1999). Die stimulering van interne lokus van beheer by werknemers binne ' $n$ finansiële instelling. Potchefstroom: PU vir $\mathrm{CHO}$.

Els, D.A., Linde, L.H. \& Rothmann, S. (2001). Die evaluering van ' $n$ ontwikkelingsprogram gerig op werknemers se lokus van beheer. Journal of Industrial Psychology, 27 (3), 24-29.

Feldt, T., Kivimaki, M, Rantala, A. \& Tolvanen, A. (2004). Sense of coherence and work characteristics: A cross-lagged structural equation model among managers. Journal of Occupational and Organizational Psychology, 77 (3), 323-41.

Fernandez, C.S.P. (2007). Emotional intelligence in the workplace. Journal of Public Health Management and Practice, 13 (1), 8083.

Frenz, A.W., Carey, M.P. \& Jorgensen, R.S. (1993). Psychometric evaluation of Antonovsky's sense of coherence scale. Psychological Assessment, 5, 145-153.

Galanos, A.N. Strauss, R.P. \& Pieper, C.F. (1994). Sociodemographic correlates of health beliefs among Black and White community dwelling elderly individuals. International Journal of Aging and Human Development, 38, 339-350.

Gibbs, N. (1995). The EQ factor. Time Magazine, 146 (14), 68-75.

Goleman, D. (1998). Working with emotional intelligence. London: Bloomsbury.

Gropp, L. (2006). An exploratory factor analysis on the measurements of psychological wellness. Pretoria: Unisa.

Heider, F. (1958). Psychology of interpersonal relations. New York: Wiley.

Hjelle, L.A. \& Ziegler, D.J. (1987). Personality theories: Basic assumptions, research and applications. (2 ${ }^{\text {nd }}$ ed.). New York: McGraw-Hill.

Heiman, T. (2004). Examination of the salutogenic model, support resources, copying style and stressors among Israeli university students. Journal of Psychology, 138 (6), 505-520.
Jahoda, M. (1958). Current concepts of positive mental health. New York: Basic Books.

Jordaan, W.J. \& Jordaan, J. (1992). Man in context. Johannesburg: Lexicon.

Jung, D. \& Sosik, J.J. (2006). Who are the spellbinders? Identifying personal attributes of charismatic leaders. Journal of Leadership and Organizational Studies, 12 (4), 12-26.

Kalimo, R. \& Vuori, J. (1991). Work factors and health: The predictive role of pre-employment experiences. Journal of Occupational Psychology, 64, 97-115.

Keegan, G (2002). The humanistic approach. Psychology Review, 9 (2), 6-9.

Kerr, R., Garvin, J., Heaton, N. \& Boyle, E. (2006). Emotional intelligence and leadership effectiveness. Leadership \& Organization Development Journal, 27 (4), 365-279.

Klavetter, R.E. \& Moagar, R.E. (1967). Stability and internal consistency of a measure of self-actualisation. Psychological Reports, 21, 422-424.

Klein, J. \& Wasserstein-Warnet, M. (2000). Predictive validity of the locus of control test in selection of school administrators. Journal of Educational Administration, 38 (1), 7-25.

Knapp, R. (1976). Handbook for the Personal Orientation Inventory. San Diego, Calif: Edits.

Kozma, A., Stones, M.J. \& McNeil, J.K. (1991). Psychological wellbeing in later life. Toronto: Butterworths.

Lefcourt, H.M. (1981). Research with the locus of control construct. New York: Academic.

Le Roux, C.A., Schmidt, C. \& Schepers, J.M. (1997). Achievement motivation, locus of control and individuality as predictors of participative management in the SA educational environment. Journal of Industrial Psychology, 23 (3), 1-8.

Maslow, A.H. (1954). Motivation and personality. New York: Harper.

Mbiti, J.S. (1990). African religions and philosophy. London: Heinemann.

Meyer, W., Moore, C. \& Viljoen, H. (2003). Personology: From individual to ecosystemI ( $3^{\text {rd }}$ ed.). Sandown: Heinemann.

Moomal, Z. (1999). The relationship between meaning in life and mental wellbeing. South African Journal of Psychology, 29 (1), 36-41.

Palmer, B., Wll, M., Burgess, Z. \& Stough, C. (2001). Emotional intelligence and effective leadership. Leadership \& Organization Development Journal, 22 (1), 5-10.

Phillips, W.M. (1980). Purpose in life, depression and locus of control. Journal of Clinical Psychology, 36, 661-667.

Pretorius, J. \& Le Roux, J. (1998). Milieu deprivation: Its implications for education in the Republic of South Africa. Adolescence, 33 (131), 689-696.

Reker, G. (1977). The purpose-in-life test in an inmate population: An empirical investigation. Journal of Clinical Psychology, 33, 688-693.

Rogers, C.R. (1961). On becoming a person: A therapist's view of psychotherapy. Boston: Houghton Mifflin.

Rotter, J.B. (1966). Generalized expectancies for internal versus external control of reinforcement. Psychological Monographs: General \& Applied. 80 (1). Whole No 609.

Salovey, P. \& Mayer, J.D. (1993). The intelligence of emotional intelligence. Intelligence 17, 433-442.

Salovey, P., Mayer, J.D. \& Caruso, D. (2002). The positive psychology of emotional intelligence. In C.R. Snyder \& S.J. Lopez (eds.), Handbook of positive psychology (pp.159-171). New York: Oxford University Press.

Sammon, S.D., Reznikoff, M. \& Geisenger, K.F. (1985). Psychosocial development and stressful life events among religious professionals. Journal of Personality and Social Psychology, 48, 676-687.

Schulz, G.M. (1994). Reliability and validity of the Personal Orientation Inventory in South Africa. Pretoria: Unisa.

Schepers, J.M. (1995). Die lokus van beheervraelys: Konstruksie en evaluering van ' $n$ nuwe meetinstrument. Johannesburg: RAU. 
Schepers, J.M. (2004). Overcoming the effects of differential skewness of test items in scale construction. South African Journal of Industrial Psychology, 30 (4), 27-43.

Schepers, J.M., Gropp. L., Geldenhuys, D.J. (2006). The factor structure, metrical properties and convergent validity of the third edition (1999) of the locus of control inventory. South African Journal of industrial Psychology, 32 (2), 1-8.

Schutte, N.S. \& Malouff, J.M. (1999). Measuring Emotional Intelligence and related constructs. New York: Edwin Mellen.

Seeman, J. (1989). Toward a Model of Positive Health. American Psychologist, 44 (8), 1099-1109.

Shostrom, E.L. (1964). An inventory for the measurement of selfactualisation. Educational and Psychological Measurement, 24 (2), 207-218.

Shostrom, E.L. (1974). Manual for the Personality Orientation Inventory. (rev. ed.). San Diego, California: EDITS.

Slaski, A.M. \& Cartwright, S. (2002). Health, performance and emotional intelligence: An exploratory study of retail managers. Stress and Health, 18, 63-68.

Snyder, C.R. \& Lopez, S.J. (2002). Handbook of positive psychology. New York: Oxford University Press.

Stonefield, N. (1999). Confirmatory factor analysis of the Personal Orientation Inventory (POI). Pretoria: Unisa.

Strauser, D.R. \& Lustig, D.C. (2003). The moderating effect of sense of coherence on work adjustment. Journal of Employment Counseling. 40 (3), 129-141.

Str mpfer, D.J.W. (1990). Salutogenesis: A new paradigm. South African Journal of Psychology, 20 (4), 265-276.
Str mpfer, D.J.W. \& Wissing, M.P. (1998). Review of South African data on the sense of coherence scale as a measure of fortigenesis and salutogenesis. Paper presented at the National Congress of the Psychology Society of South Africa, Durban.

Sunbul, A.M. (2003). An analysis of relations among locus of control, burnout and job satisfaction in Turkish high school teachers. Australian Journal of Education, 47 (1), 58-73.

Van Eeden, C. (1996). Psigologiese welstand en koherensin. Ongepubliseerde Ph.D. tesis, Potchefstroom: PU vir CHO.

Visser, C. (1994). 'n Psigometriese ondersoek na psigologiese optimaliteit. Pretoria: Unisa.

Wade, J.T. (1996). An examination of locus of control/ fatalism for Blacks, Whites, boys, and girlsover a two-year period of adolescence. Social Behavior and Personality, 24, 239-248.

Walker, H. (2002). Clarification of the affective component of psychological wellbeing. Paper presented at the International EQ Conference, 19-20 June 2002. Durban, South Africa.

Walsh, R. \& Shapiro, D.H. (1983). Beyond health and normality: Explorations of exceptional psychological wellbeing. New York: Van Notstrand Reinhold.

Witmer, J.M. \& Sweeney, T.J. (1992). A holistic model for wellness and prevention over the life span. Journal of Counselling and Development. 71, 140-148.

Yarnell, T.D. (1971). Purpose-in-life test: Further correlates. Journal of Clinical Psychology. 27, 76-79. 